\title{
Characteristics of high enjoyment teachers of mathematics in primary schools
}

\author{
James Russo ${ }^{1}$ (D) - Janette Bobis ${ }^{2} \cdot$ Ann Downton ${ }^{1} \cdot$ Maggie Feng $^{2}$. \\ Sally Hughes ${ }^{1} \cdot$ Sharyn Livy $^{1} \cdot$ Melody McCormick ${ }^{1} \cdot$ Peter Sullivan $^{1}$
}

Received: 28 November 2020 / Revised: 26 January 2021 / Accepted: 2 February 2021 /

Published online: 17 February 2021

(c) The Author(s) 2021

\begin{abstract}
Despite teacher enjoyment of teaching being associated with a range of benefits for teachers and their students, little research exploring the characteristics of teachers who enjoy teaching mathematics exists. Semi-structured interviews were conducted with ten teachers who scored in the top third in terms of their enjoyment of teaching mathematics from a sample of 118 generalist, early-year primary school teachers. Thematic analysis of interview data revealed that negative-to-positive turning point experiences were commonplace amongst high-enjoyment primary teachers, but so too were reports of consistently positive feelings towards mathematics throughout their entire lives. While most articulated a passion for teaching mathematics, all teachers considered instances when students experienced 'light bulb' moments in their mathematical understanding that made a mathematics lesson enjoyable to teach. An important implication of our research is that one need not be a 'maths person' to come to love teaching mathematics. Rather, positive experiences in one's pre-service teacher education, or in-service teacher professional learning, have the potential to transform one's attitude towards teaching mathematics.
\end{abstract}

Keywords Teacher attitudes $\cdot$ Teacher enjoyment $\cdot$ Turning points $\cdot$ Mathematics teaching $\cdot$ Primary teaching

\section{Introduction}

Teacher enjoyment of teaching mathematics is positively associated with a number of valued outcomes, such as a willingness to spend more time teaching mathematics and to encourage productive struggle with more cognitively demanding tasks (Russo

\section{James Russo}

james.russo@monash.edu; mr.james.russo@gmail.com

1 Faculty of Education, Monash University, Melbourne, Australia

2 The University of Sydney, Sydney, Australia 
et al., 2020), self-confidence and efficacy as a teacher (Stipek et al., 2001), high levels of energy and reduced teacher burnout (Frenzel et al., 2016), high-quality student-teacher relationships (Taxer et al., 2019), increased student enjoyment (Frenzel et al., 2018) and student motivation to learn mathematics (Russo \& Russo, 2019).

However, despite the clear benefits of cultivating teacher enjoyment for teachers and their students, relatively little is known about the characteristics of highenjoyment teachers of mathematics. Is enjoyment of teaching mathematics malleable, or are high-enjoyment teachers of mathematics likely to have held positive views towards mathematics across their lifespans? Do generalist primary teachers who report being high-enjoyment teachers of mathematics particularly enjoy mathematics teaching, or are they better understood as individuals who enjoy teaching in general? Finally, what is it specifically about teaching a mathematics lesson that leads to these teachers' enjoyment of teaching the subject? This study aims to shed light on such characteristics of high-enjoyment teachers of mathematics currently teaching in the early years of primary school (Foundation, Year 1 and Year 2).

\section{Background literature}

Emotions are mostly conceived as multicomponential (Sutton \& Wheatley, 2003), involving systematic changes in a range of cognitive, physiological and expressive components. An emotional process might begin as a subjective appraisal (cognitive component) evoked by a context. Physiological changes such as increased heart rate might follow and be accompanied by an emotional expression (change in voice pitch or facial expression). Because emotional processes are triggered by a subjective interpretation or appraisal of a situation, each individual may respond differently to the same context. Frenzel et al. $(2009,2016)$ applied a componential, appraisal-based framework to explain teacher cognitive judgements about events in the classroom, to better understand how teacher emotions link to instructional behaviours conducive to quality teaching. Understanding how emotions arise in relation to teaching practice is complex. For example, Frenzel (2014) speculated that some emotions, particularly social negative emotions such as shame and guilt, may only emerge retrospectively when reflecting back on a particular teaching period, or making a global evaluation in relation to oneself as a teacher.

Mathematics anxiety is one specific topic in the context of the roles of emotions in the teaching of mathematics that has been addressed to some extent in the literature (see, for example, Beilock et al., 2010; Brady \& Bowd, 2005; Buckley et al., 2016; Bursal \& Paznokas, 2006; Bush, 1989; Gabriel et al., 2020; Gresham, 2008, 2018; Haciomeroglu, 2014; Hollingsworth \& Knight-McKenna, 2018). Another issue that has been the subject of research attention only more recently is the notion of teacher enjoyment, particularly in relation to teaching mathematics (Frenzel et al., 2009, 2018; Marbán et al., 2020; Russo et al., 2020; Russo \& Russo, 2019).

Enjoyment as an emotional state arises from engaging in activities an individual values, finds interesting and has a substantial degree of control over (Pekrun, 2006). Enjoyment of teaching can be framed as a subset of activity-related enjoyment. There 
is some evidence that the level of enjoyment experienced while teaching depends both on a teacher's enjoyment of teaching a specific subject, as well as a more general propensity to enjoy (or not enjoy) teaching, independent of the subject (Frenzel et al., 2015). Teacher enjoyment has been distinguished from teacher enthusiasm by construing the former as internal and subjective, and the latter as behavioural and observable, although the two constructs have been found to be positively correlated (Frenzel et al., 2009). It has been suggested in the literature that teacher enjoyment of mathematics teaching in particular may arise from the teacher facilitating a 'light bulb' or 'Aha!' moment, where a teacher supports a student to understand a mathematical idea or make an important connection between mathematical ideas for the first time (Russo et al., 2020, p. 9). Furthermore, providing teachers with more autonomy, including opportunities to explore mathematics through inquiry-based topic areas, of interest to both themselves and their students, can enhance teacher enjoyment of teaching mathematics (Russo \& Russo, 2019).

The substantial benefits that accrue to both high enjoyment teachers themselves (e.g. lower burnout) and their students (e.g. increased student motivation) outlined earlier suggest that enjoyment of teaching mathematics warrants being the subject of intensive research. However, a further reason to focus on the emotion of teacher enjoyment in particular is the evidence that it is the dominant discrete emotion reported by teachers in the classroom (Frenzel, 2014). For example, using a teaching diary methodology, Frenzel and Goetz (2007) found that teachers in their study were four times more likely to agree or strongly agree that they had experienced enjoyment or happiness in their previous teaching period compared with the negative emotions of anger or anxiety. It is interesting to note that the issue of mathematics anxiety amongst primary school teachers has received more attention in the literature than enjoyment of teaching mathematics, despite the emotion of enjoyment being far more frequently reported than anxiety, at least using in vivo measures.

Several recent studies have considered the characteristics that lead to some teachers enjoying teaching more than others, including mathematics teaching. Such research conceptualises teacher enjoyment as a (somewhat) stable trait, in contrast to Frenzel and Goetz's (2007) earlier study that understood enjoyment as one possible emotional state experienced whilst teaching. Russo et al. (2020) argued that in the context of teaching with cognitively demanding mathematical tasks, possessing high levels of pedagogical content knowledge, high levels of self-confidence and a comfort with student-centred pedagogies will result in a teacher experiencing a greater level of control, leading to higher levels of teaching enjoyment. By contrast, low levels of pedagogical content knowledge and self-confidence, and a lack of familiarity with student-centred pedagogies, will lead to lower levels of control, and thus feelings of anxiety and lower levels of teaching enjoyment.

Frenzel et al. (2020) examined the extent to which teacher enjoyment could be explained by teachers perceiving their classroom environments to be characterised by high student performance, motivation, discipline and high-quality teacherstudent relationships. Using a self-report questionnaire methodology involving 244 Germany secondary school teachers who taught a variety of subjects, they found that teachers who perceived their relationships with their students as higher quality, and to a lesser extent those who perceived their students as more motivated, enjoyed 
teaching more. Teachers' perceptions of their actual classroom environments were far more important for explaining differences in teacher enjoyment between teachers than the extent to which they valued these characteristics.

Adopting a similar design to Frenzel et al. (2020), but focussing on pre-service primary teachers based in Spain $(n=1473)$, Marbán et al. (2020) found that a high level of mathematics self-concept (e.g. self-perception that one is skilled/confident when doing mathematics) and a low level of mathematics anxiety were strongly related to enjoyment of doing mathematics, which in turn predicted enjoyment of teaching mathematics. Marbán et al. suggested that whilst it is reasonable to be cautiously optimistic about well-targeted interventions reducing mathematics anxiety (leading to increased enjoyment of teaching mathematics), mathematics self-concept is less likely to be malleable: 'It is important to note that a student's mathematics self-concept is defined by all their experiences related to math, and as such is resistant to changes established in the medium and long term' (p. 13). In any case, the authors concluded that focussing more explicitly and centrally on the affective domain during pre-service teacher education courses has merit, given that 'the desire to teach mathematics in the initial educational levels is key to the improvement of mathematics performance in school' (p. 14). In light of Marbán et al.'s (2020) postulations, it is interesting to note that Gresham (2018) found some evidence that the most mathematics-anxious pre-service teachers became significantly less anxious after several years of teaching practice, although still remained comparatively mathematics-anxious as in-service teachers.

A further body of research, rather than studying teacher emotions as they arise (e.g. Frenzel \& Goetz, 2007), or global emotions at a particular point in time (e.g. Frenzel et al., 2020; Marbán et al., 2020; Russo et al., 2020), has instead focused on shifts in emotions in relation to teaching and learning mathematics over a teacher's lifespan (Towers et al., 2017). Such research has tended to emphasise analysing narrative accounts provided by pre-service (e.g. Ellsworth \& Buss, 2000) or in-service (e.g. Drake, 2006) teachers and has often revealed specific turning points across their lifespan in relation to feelings towards mathematics.

Guillaume and Kirtman (2010) asked 144 pre-service teachers (US primary education majors) to provide narrative accounts about their experiences with mathematics across their education, as well as construct line graph representations that tracked both their self-reported mathematical performance and attitude towards mathematics across their life span. Their study revealed that the majority of participating pre-service teachers currently held positive attitudes towards mathematics (57\%), whilst a comparatively small number held negative attitudes (19\%). Interestingly, $81 \%$ of pre-service teachers' line graph representations of their mathematical life experiences were characterised by both clear peaks and troughs, suggesting that particular events influenced their attitudes towards mathematics both positively and negatively. Analysis of participant narratives revealed such peaks and troughs to be generated by one of four types of events: the presence of a powerful teacher (e.g. a teacher who brought mathematics to life through authentic tasks), engagement with a particular topic (e.g. first exposure to formal algebra), experience with assessment (e.g. failing a high-stakes exam) or a particular stage in their socio-emotional development (e.g. moving away from 
school mathematics and focusing on peer relationships). The authors noted that this contrasts with student narratives about their development as readers, which tend to follow clearer, more linear paths.

Ellsworth and Buss (2000) reported on 61 pre-service teachers, again US primary education majors, 'mathematical autobiographies' across their K-16 schooling. Initial analysis revealed the overall attitude towards mathematics to be consistently negative $(33 \%)$, consistently positive $(25 \%)$, negative to positive $(26 \%)$ or positive to negative (16\%). In contrast to the Guillaume and Kirtman (2010) study, around half (49\%) of the pre-service teachers conveyed stories underpinned by a current negative stance towards mathematics, whilst only a minority (42\%) told a mathematical autobiography punctuated by a clear turning point. Further analysis of these autobiographies revealed the strongest influence on the valence of mathematical autobiographies to be attributable to teacher effects, which was mentioned by over three-quarters of participants. Other notable influences included family members, the perceived relevance (or irrelevance) of the subject, the pace at which content was covered and the related emphasis on skill practice and memorisation in instruction.

Drake (2006) interviewed 20 in-service US primary teachers and asked them to construct a mathematics story incorporating their early experiences with mathematics, as well as how they currently perceived themselves as a learner and teacher of mathematics. Study teachers were equally divided between those that told a story predominantly characterised by a specific failure with mathematics in their schooling and those teachers that told stories characterised by a mixture of positive and negative feelings towards mathematics at school. In terms of their current attitudes, almost half of the teachers $(45 \%)$ currently described feeling positive about teaching and learning mathematics, and almost half (45\%) felt positive only about teaching mathematics. Only two teachers (10\%) held negative views about teaching and learning mathematics. Drake concluded that six of the study teachers (30\%) told turning point stories, which were defined as: 'stories in which an individual's very negative early experiences with learning and teaching mathematics have recently been transformed by an experience (the turning point) in which the teacher's understandings about mathematics, learning mathematics, and teaching mathematics changed substantially' (p. 589). Further analysis of these turning point stories revealed that three of these individuals attributed their dramatic shift in attitude towards mathematics to the lived experience of teaching mathematics to primary aged children, whereas the other three attributed this shift to their experience as an adult student learning about how to be an effective mathematics teacher.

\section{Theoretical framework}

Teacher enjoyment of teaching mathematics is an important construct with clear implications for both student exposure to quality pedagogy (Russo et al., 2020), and the student affective experience of learning mathematics (Frenzel et al., 2009). However, there have been relatively few attempts to understand the characteristics of high-enjoyment teachers of mathematics within a primary school environment. 
To summarise, using what is known and theorised from the literature about the relationship between teacher enjoyment of teaching mathematics and other teacher characteristics, we might expect a high-enjoyment teacher of mathematics to:

1. Describe having positive relationships with students in their classroom and perceive students in their classroom as being motivated to learn mathematics (Frenzel et al., 2020)

2. Have a high level of sensitivity to student positive emotional displays, particularly those involving light bulb or Aha moments (Russo et al., 2020, p. 9)

3. Be provided with autonomy, including opportunities to plan learning experiences that align both with personal interests and passions and those of their students (Russo \& Russo, 2019)

4. Possess self-confidence as a mathematics teacher, high levels of pedagogical content knowledge and perceive themselves to be in control even when operating in student-centred learning environments involving work on cognitively demanding tasks (Russo et al., 2020);

5. Report low levels of mathematics anxiety and high level of mathematics selfconcept as mathematics learners (Marbán et al., 2020)

6 . Either communicate a consistently positive narrative about their experience of mathematics as a learner across their lifespan or describe some sort of turning point where they previously held negative or ambivalent attitudes towards mathematics but are now positively disposed to the subject (Drake, 2006; Ellsworth \& Buss, 2000; Guillaume \& Kirtman, 2010)

Self-determination theory can be used to shed light on what we understand about teacher enjoyment of teaching mathematics. Proponents of self-determination theory suggest that three fundamental psychological needs motivate behaviour: autonomy, competence and relatedness, and that meeting these needs is important for an individual's psychological wellbeing and satisfaction (Deci \& Ryan, 2012). Autonomy refers to 'the need to self-regulate one's experiences and actions '; it is 'associated with feeling volitional, congruent and integrated' (Ryan \& Deci, 2017, p. 10). Competence covers 'our basic need to feel effectance and mastery,' particularly the feeling that one is operating effectively within 'important life contexts' (p. 11). Finally, relatedness involves 'feeling socially connected' and includes both feeling cared for, as well as 'experiencing oneself as giving or contributing to others' (p. 11).

Existing research into teacher enjoyment of teaching mathematics can be reframed such that enjoyment is an outcome experienced by teachers that have these three basic psychological needs met while teaching mathematics. The model in Fig. 1 presents existing research into teacher enjoyment of teaching mathematics through a self-determination theory lens. Specifically, each of the six summary points previously identified is connected to at least one of the three basic psychological needs of autonomy, competence and relatedness in the model. For instance, consider Frenzel et al.'s (2020) finding that having positive relationships with students in their classrooms was the most important classroom environmental characteristic for explaining variance between the enjoyment levels experienced by 
Fig. 1 Self-determination theory: basic psychological needs and their relationship to teacher enjoyment of teaching mathematics

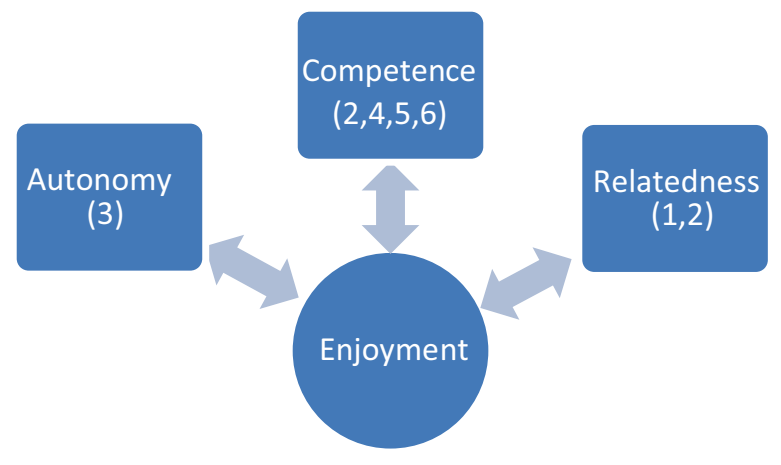

teachers (summary point 1 ). Having positive relationships with students meets the need for relatedness, thereby enhancing teacher enjoyment.

It is worth noting that some of these summary points appear to connect to multiple psychological needs. To illustrate, consider summary point 2 . It can be argued that being a teacher who possesses a high level of sensitivity to student positive emotional displays (e.g. light bulb moments) will be more likely to have their need for relatedness met whilst teaching mathematics than a teacher with a comparatively low level of sensitivity, and thus experience more enjoyment. However, it is likely that facilitating light bulb moments also generates feelings of self-efficacy in a teacher, and therefore also meets a teacher's need for competence, leading to enjoyment.

As is indicated by the bi-directional arrows in Fig. 1, we contend that as well as being an outcome of meeting the basic psychological needs of autonomy, competence and relatedness, experiencing enjoyment will galvanise teachers into taking actions that can further enhance these psychological needs. For example, consider a teacher with a high level of mathematical pedagogical content knowledge who feels competent teaching mathematics, and thus enjoys being a mathematics teacher. It is likely that this teacher is motivated by the satisfaction they obtain from teaching mathematics to seek out professional learning opportunities in order to further cultivate and deepen their expertise. This will in turn further develop their pedagogical content knowledge and self-confidence as a mathematics teacher, leading to more intense feelings of enjoyment, and thus generating a virtuous circle.

\section{The current study}

To some extent, our discussion and theorising around high-enjoyment teachers of mathematics remains speculative, as studies to date have not focussed on highenjoyment teachers specifically, but rather examined correlations between levels of teacher enjoyment and a variety of other factors amongst broad populations of teachers. Consequently, important questions remain to be addressed about those primary school teachers who highly enjoy mathematics teaching. For instance, are the teachers who highly enjoy teaching mathematics best understood as having 
well-developed mathematics self-concepts, a trait that has been suggested to be relatively resistant to change (Marbán et al., 2020)? If so, this might suggest that highenjoyment teachers of mathematics have their destinies determined before they enter their teacher education course. On the other hand, there is evidence, including among in-service primary teachers (Drake, 2006), that many teachers who now enjoy teaching and learning mathematics had experiences of mathematics at school that were either predominantly negative, or at best ambivalent, suggesting some sort of turning point in their attitude towards mathematics. However, because of the methodologies adopted in previous studies, it is difficult to know whether those teachers who most enjoy teaching mathematics experienced such turning points, given that the majority of primary teachers report negative or ambivalent feelings towards learning mathematics when a student at school (Ellsworth \& Buss, 2000; Guillaume \& Kirtman, 2010), but that most primary teachers have positive attitudes towards teaching, including teaching mathematics (Guillaume \& Kirtman, 2010; Russo et al., 2020).

This paper therefore has three aims pertaining to better understanding the characteristics of high-enjoyment teachers of mathematics currently teaching in the early years of primary school:

1. To explore the attitudes of these teachers towards teaching and learning mathematics across their lifespan, with a particular focus on identifying any potential turning points in their attitudes

2. To compare and contrast these teachers' attitudes towards teaching mathematics with their attitudes towards teaching in general.

3. To examine what it is about teaching a mathematics lesson specifically that these teachers perceive as enjoyable

\section{Method}

Prior to participating in a professional learning program targeted at generalist primary school teachers currently teaching in the early years (Foundation, Year 1, Year 2), 118 teachers, from 26 different primary schools in Victoria, Australia, completed the Teacher Enjoyment of Teaching Mathematics measure as part of their pre-program questionnaire. The measure contained five items. The items were measured on 5-point Likert scales, as per the Frenzel et al. (2009) study, ranging from strongly disagree (1) to strongly agree (5).

- I really enjoy teaching mathematics

- I look forward to mathematics lessons

- Teaching mathematics is so enjoyable that I like preparing and planning my lessons

- When teaching mathematics, I am good-humoured

- Teaching mathematics gives me many reasons to be pleased 
The maximum possible score on this measure is 25 , and the minimum score is 5 . The measure has been shown to have good psychometric properties, including high reliability (Frenzel et al., 2009; $\alpha=0.90$ ).

Only participants with current teaching responsibilities in the early years of schooling were included in the analysis. Across the 118 generalist primary teachers, currently teaching in the early years, who completed the questionnaire, the mean score on the measure was 20.2, whilst both the median and modal scores were 20 . This indicates that teachers, on average, agreed that that they enjoyed teaching mathematics. Further inspection revealed that scoring 22 or above on the measure indicated that teachers were in the top third in our sample (specifically top 31\%) in terms of their enjoyment of teaching mathematics. We classified these individuals as high-enjoyment teachers (of mathematics). ${ }^{1}$

There is further evidence that a score of 22 or above warrants being classified as a high-enjoyment teacher of mathematics, drawing on other datasets that have employed the Teacher Enjoyment of Teaching Mathematics measure. For example, extrapolating from the reported means and standard deviations, a score of 22 or above would have placed one in the top $15 \%$ in the Frenzel et al. (2009) study for teacher enjoyment (sample: year 8 secondary teachers in Germany).

Of the 118 teachers, 37 were classified as high-enjoyment teachers. On a convenience basis, 10 of these teachers were then invited to participate in semistructured interviews designed to probe their experience teaching mathematics, why they enjoyed teaching the subject, how teaching it compared with their experience of teaching other subjects and their more general experiences of mathematics as children and adults. All 10 individuals agreed to participate in semi-structured interviews. Most participants interviewed $(n=7)$ were established in the profession, having been teaching between 6 and 11 years, although three of the participants in our sample were new graduates (i.e. in their first 2 years of teaching). For a summary profile of study participants, see Table 1.

Interviews were undertaken face-to-face, with the duration of these interviews being between $19 \mathrm{~min}$ and $38 \mathrm{~min}$ (median = $30 \mathrm{~min}$ ). Interview data was subsequently transcribed and analysed thematically following the six stages put forward by Braun and Clarke (2006); that is, (1) familiarisation with the data, (2) generating initial codes, (3) searching for themes, (4) reviewing themes, (5) defining and naming themes and finally, (6) producing the report. The relatively small number of participants and the rich data gleaned through the interview process meant that

\footnotetext{
1 Based on the cut-offs from our sample, we classified a score of 18 or less as a (relatively) lowenjoyment teacher of mathematics (corresponding to 33 teachers; or $28 \%$ of our sample), and a score in the range of 19-21 as a medium-enjoyment teacher of mathematics (corresponding to 48 teachers; $41 \%$ of our sample). Additional analysis revealed that the high-enjoyment teachers scored significantly higher on all five items on the Teacher Enjoyment of Teaching Mathematics measure than low-enjoyment teachers $(p<0.01)$. The largest differences between high enjoyment and low enjoyment teachers were for item 2, whether they looked forward to their mathematics lessons (mean difference $=1.7$; highenjoyment teachers, $M=4.9$; low-enjoyment teachers, $M=3.2$ ), and for item 3 , whether they found mathematics teaching so enjoyable that they liked preparing and planning lessons (mean difference = 1.6; high-enjoyment teachers, $M=4.6$; low-enjoyment teachers, $M=3.0$ ).
} 
Table 1 Study participants: years' experience and current grade level teaching

\begin{tabular}{lll}
\hline & Years' experience & $\begin{array}{l}\text { Current grade } \\
\text { level teaching }\end{array}$ \\
\hline Larissa & 9 & Year 1 \\
Jen & 6 & Year 1 \\
Penelope & 7 & Year $1 / 2^{*}$ \\
Steph & 9 & Year $1 / 2$ \\
Julie & 11 & Foundation* \\
Dane & 2 & Year 2 \\
Sarah & 1 & Year $1 / 2$ \\
Fiona & 2 & Foundation \\
Jane & 7 & Year $1 / 2$ \\
Ellen & 10 & Year $1 / 2$ \\
\hline
\end{tabular}

*Also has a role in their school as a mathematics leader (see Grootenboer et al., 2015, and Sexton, 2019, for a discussion of what this leadership role entails)

there was an emphasis on capturing and conveying individual participant stories to illustrate and unpack important themes. The flexibility of thematic analysis makes it suitable for either studies involving limited text responses from larger samples and those involving in-depth interviews from smaller samples, such as the current study (Braun \& Clarke, 2006).

\section{Results and discussion}

This section is organised according to three themes that emerged from an analysis of the ten interviews, which in turn were shaped by the questions asked of participants and the aims of the study more broadly. The first two themes, which effectively inform the first two study aims, are presented as tensions between the different participant narrative accounts, and have been framed as questions. They are:

- Turning points, or a persistent enjoyment of mathematics?

- A love of teaching mathematics, or simply a love of teaching?

The third theme, by contrast, emerged as a consensus explanation as to what it is about teaching a mathematics lesson that makes it enjoyable to teach and addresses the third aim of the study. The theme can be described as facilitating light bulb moments.

\section{Turning points or a persistent enjoyment of mathematics?}

It is interesting to consider whether the high-enjoyment teachers identified as part of the current study have always enjoyed mathematics, or whether they have overcome some earlier challenging experiences with the subject to grow to enjoy 
teaching mathematics. If the latter is the case, it suggests that primary teacher attitudes towards teaching mathematics are at least somewhat malleable, positive feelings towards the subject can be cultivated, and high-enjoyment teachers cannot simply be dismissed as 'maths people'. Analysis of the interviews revealed that three of the teachers (Dane, Jen and Penelope) enjoyed mathematics throughout their schooling. In fact, Dane and Jen were self-described maths people. Dane was a qualified secondary mathematics teacher, and Jen began studying architecture at university because it provided her with an opportunity to apply her mathematical knowledge.

I'm a maths person. So I was pretty okay at maths [at school]. It was definitely one of my strengths; it was definitely my best subject. So yeah, I really enjoyed it... My course at [university] was actually Prep [Foundation] to Year 12. So I specialised in maths, teaching for secondary schools. Dane. Maths was always my favourite subject; I think I'm quite naturally good at it. I like how black and white it is. [At school] I loved it, like I really enjoyed it... I picked up the real-life application of it quite easily, so I quite enjoy still using it now for like building things and like drawing, all that kind of stuff. Yeah, I originally went to go study architecture because of the maths side of it. Jen.

The third teacher with consistently positive feelings towards mathematics across her schooling was Penelope. Penelope always knew she wanted to be a primary school teacher, so was not interested in specialising in mathematics, however always felt competent at mathematics throughout her schooling:

I've always really liked maths. Primary school I do remember, it was about the process. You had to learn the process. I still remember, I think maybe Year 4, when I understood the algorithm for multiplication; I was like 'Yes.' Do you remember that moment? And I've always kind of got the processes, kind of always been good at maths. Secondary school, I did the 'easy' maths, because I always wanted to be a teacher... I loved that.

By contrast, the remaining seven teachers interviewed described having negative feelings about mathematics as a student in school, before experiencing a subsequent turning point that has eventually led them to love teaching mathematics. For Ellen and Steph, this turning point came during their later years of secondary school, whereas for Jane, Fiona, Sarah and Larissa, it was associated with their pre-service teacher education, and for Julie, it was through her participation in a professional learning initiative as an in-service teacher.

Although Ellen and Steph both experienced a dramatic shift in their view of mathematics at school, each reported vastly different catalysts for these shifts. Ellen struggled to make sense of mathematics at primary school, noting that there were 'a lot of worksheets... no manipulatives, like, you never got to touch anything '. However, during secondary school, she had a 'phenomenal maths teacher' for 2 years (Year 9 and Year 10) who supported her to feel confident and competent using mathematics. Although she did not take advanced mathematics 
subjects in her final years of schooling, she maintained her positive attitude towards mathematics and her sense of being a numerate person who could apply mathematics to solve real world problems (e.g. 'read data, understand data, compare data, and all that '). These positive feelings towards mathematics continued to develop through her pre-service teacher education course.

Whereas Ellen attributed her embracing of mathematics in secondary school to a transformational teacher, Steph ironically described how it was having a mathematics teacher in her final 2 years of schooling (Year 11 and Year 12) who was 'really shocking at his job' that galvanised her to become a teacher in the first instance. Steph described how mathematics, which she felt had always been a relative strength of hers, became incomprehensible. However, perhaps reassuringly, almost all her classmates felt similarly. Consequently, Steph sought out private tuition, learned the mathematics content herself and proceeded to teach it to her classmates. This inspired her to pursue a teaching degree. Steph is primary and secondary qualified, with mathematics being one of her secondary methods.

The experiences of Ellen and Steph resonate with prior research identifying salient positive and/or negative encounters with specific classroom teachers as catalysts for turning points in terms of how a future teacher feels about mathematics (Ellsworth \& Buss, 2000; Guillaume \& Kirtman, 2010). Although probably unusual, Steph's account is an important reminder that it is problematic to simply assume that a negative experience with a teacher will lead one to adopt a negative view of mathematics.

Half of the teachers interviewed described a turning point about how they felt about mathematics during their pre-service teacher education (Jane, Fiona, Sarah and Larissa), or during in-service teacher professional learning (Julie), after either being relatively indifferent towards mathematics at school (Jane, Larissa), or actively disliking it (Fiona, Sarah, Julie). For all of these teachers, their school experience of mathematics was characterised by a lack of deep, relational understanding, as they were expected to apply procedures instrumentally without much interest in whether they grasped the underlying mathematical ideas (Skemp, 1976).

Whereas Larissa described some satisfaction at being able to accurately execute these procedures, she noted that learning mathematics in this manner did not set her up to be successful in the long term.

I was pretty good at copying the example off the board and then applying it to my problem until I got to Year 11 then I felt like I couldn't do any of it; it just got harder and harder. Up until Year 10 I was quite confident with maths and then Year 11 was a walkout. I didn't do it in Year 12.

For the most part, the remaining teachers were more unambiguously negative in their descriptions of learning mathematics through applying what Skemp (1976) has described as 'rules without reasons' (p. 20). Julie explained how this teaching approach led to her 'switching off' mathematics at a similar stage in her schooling to Larissa. 
I didn't enjoy it at all, I didn't understand it... it was very much 'this is the way you do it'. We'd get assessments back and there would be no discussion about where we went wrong or what you can do to improve. So I sort of switched off mathematics from about the age of 16 onwards.

Similarly, for Sarah, her secondary school experience was characterised by a passive, textbook-heavy teaching approach, which led to student confusion and isolation.

I hated it [learning mathematics in secondary school]. You're learning from a textbook and I hate that, there's no discussion, it's just quiet work, you're sitting at a textbook; there was no real teaching of it, it was just a model on the board and then that's it, 'You have to work through your problems yourself'. There was no collaboration. So, for me, I just struggled because I didn't quite understand the formulas, for me it's rote learning, I couldn't wrap my head around it.

All of these teachers went on to contrast their experience of school mathematics with either their experience of learning to teach mathematics in their pre-service teacher education course (Jane, Fiona, Sarah, Larissa) or subsequent professional learning (Julie). A significant factor in shifting how they felt about mathematics was re-learning mathematical content relationally (Skemp, 1976). Larissa, for example, described how the need to teach mathematics meant that, 'I need to be able to understand it and be able to articulate because I can't teach it by rote'. Sarah explained how lecturers in her pre-service teacher education course helped make connections between concrete materials and conceptual models, expected students to explain their thinking and justify their reasoning and provided opportunities to solve problems using multiple strategies. Sarah noted:

It was more engaging, so the lecturers were able to explain things, so getting that explanation, having the hands-on activities, the concrete materials... You didn't have to learn it this one particular way that school taught me, there were so many other ways. You don't have to have the one strategy, as long as you can find the answer and explain how you got there, that's fine.

Fiona described the mathematics she engaged with at university as challenging; however, she was encouraged by her lecturers to persist. These experiences simultaneously served to deepen her content knowledge whilst providing a model for how she might teach mathematics to her (future) students.

The maths was really quite advanced. We were given these problem books... We had to document how we worked it out, what mathematical concepts we used. They were just endlessly really putting us in that pit, like throwing you - Because I hadn't done maths in 20 years. But Uni was always reiterating that, 'You can do it. Just keep having a go'... And I use a lot of that in our classroom as well. They [the students] are all like, 'I can't do it,'- you're not allowed to say it, you can all have a go... and just really celebrating those moments when those kids that do struggle a little bit 'get it'. 
The stories of these five teachers are consistent with the literature suggesting that positive experiences as an adult student during pre-service or in-service teacher education courses can precipitate turning points in attitudes towards teaching and learning mathematics (Drake, 2006). Collectively, the accounts of teachers in our study further support the notion that turning point experiences are commonplace amongst primary teachers (Guillaume \& Kirtman, 2010), and that primary teachers are at least as likely to report a negative-to-positive turning point narrative as to have consistently positive feelings towards mathematics (Ellsworth \& Buss, 2000).

\section{A love of teaching mathematics, or simply a love of teaching?}

Another important tension that emerged through analysis of interviews with high-enjoyment teachers was whether these teachers loved or enjoyed teaching mathematics in particular, or loved teaching in general and liked teaching mathematics. The matrix presented in Fig. 2 classifies study teachers according to how they felt about teaching mathematics specifically compared with teaching in general, as well as whether they reported experiencing a turning point or instead held a consistently positive view about mathematics teaching (discussed previously).

It is apparent from viewing Fig. 2 that seven of our participants enjoyed teaching mathematics in particular. This included five teachers who had held negative or indifferent views about mathematics at the end of their secondary schooling but subsequently experienced a turning point during their pre-service teacher education

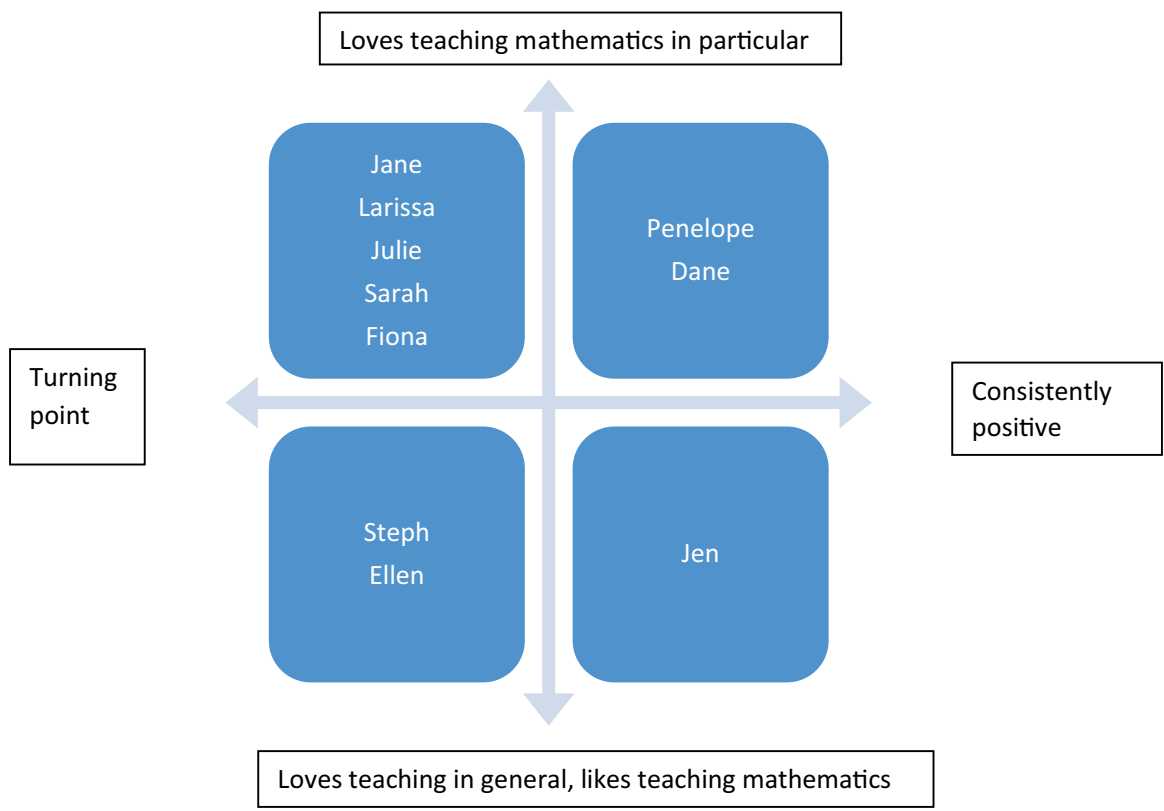

Fig. 2 Matrix classifying high-enjoyment teachers along two dimensions 
(Jane, Larissa, Sarah, Fiona) or during subsequent in-service professional learning (Julie). It also included two teachers (Penelope, Dane) who constructed consistently positive narratives about their experience of mathematics throughout their life.

The seven teachers who loved teaching mathematics in particular tended to provide three interrelated reasons as to why they enjoyed teaching mathematics specifically: (1) opportunities to facilitate deep connections and understanding, which they felt were more immediate than for other subjects (e.g. reading); (2) access to manipulatives and the 'hands-on' nature of mathematics learning, which they felt made it more accessible to students than other subjects, and (3) high levels of student engagement, relative to other subjects. Some exemplary quotes from participants include:

I think it [maths] is easily accessible as well, whereas reading is a long process... I see more growth in math because it's easier to see, it's easier to assess as well. Larissa

I like the hands-on stuff. I think kids get it and I think it's easy to explain, it's easy to - they can see it. Whereas literacy is tricky; they can't sort of see it as much, whereas you can demonstrate the concrete stuff. Jane

I can't pinpoint it. I do enjoy literacy and inquiry and religion, but I just feel with mathematics I'm more excited to teach because the activities are more engaging, the concepts are quite easy to wrap your head around, and I just think all students can achieve. Sarah

Definitely it [maths] is way more fun. Well, if you've got the right activities, there's so many things that you can do with maths. With reading, you just read. Like, how many different ways can you get them to learn the same high frequency words? Like, with maths, there's so many things that you can do. Penelope

By contrast, Steph, Ellen and Jen reported that while they enjoyed teaching mathematics, they were more passionate about other curriculum areas:

I feel like I'm excited about most subjects I teach, so that's - it's probably a hard one to answer.... I wouldn't say it [maths] like it's my fav - I'd say it's about the same. I really love teaching literacy. That's probably more of my strength. I'm doing a Masters of literacy at the moment. So I probably have a bit more knowledge. Steph

I love teaching. It's a passion of mine... I just love it. I like how it changes and it's not always the same; I love the kids. I just love it... If I had to choose out of all the subject areas, I would say that enquiry social studies is my favourite because I love learning about the world and I'm a people person. But maths is up there. So I'd say it's just under enquiry. Ellen

I wouldn't say it [maths] is my favourite subject to teach... I like it [maths], I like doing it all the time, but I think teaching it - to me teaching it is different from doing it yourself, and especially at the juniors... I think writing is 
my favourite [subject to teach], it [maths] would probably be second or third, maybe equal with reading. Jen

To summarise, most of the teachers $(n=7)$ in our study articulated a passion for teaching mathematics in particular; however, some teachers $(n=3)$ were better understood as passionate teachers who simply liked teaching mathematics. This distinction was worth exploring, particularly given there is evidence that teacher enjoyment of mathematics is likely to depend both on subject-specific preferences, and general enjoyment of teaching (Frenzel et al., 2015). Consequently, it was not surprising that our methodology of classifying high-enjoyment teachers would capture both teaching enthusiasts and mathematics-teaching enthusiasts. The next theme explores what it is in particular about teaching a mathematics lesson that our study teachers enjoy.

\section{What makes a mathematics lesson enjoyable to teach: facilitating light bulb moments}

Beyond asking teachers more generally what they enjoyed about teaching mathematics relative to other subjects (if they held this view), all participants were also asked to describe what it was specifically about teaching a mathematics lesson that led to feelings of enjoyment. All teachers emphasised that it was directly experiencing students making mathematical connections; gaining a new, deep understanding of a concept and having light bulb or Aha moments that made an actual mathematics lesson enjoyable to teach. For example:

I think that light bulb moment that's when I go, 'they get it'. That's what I like to see. Larissa

I'm excited that I can move these kids, and really see their growth. I've got an opportunity to really make a difference in their life. Steph

Student understanding, yeah, makes it enjoyable. Dane

This finding is consistent with anecdotal evidence reported in the literature that light bulb or Aha moments are likely a central source of teacher enjoyment of teaching mathematics, as well as the hypothesis that high-enjoyment teachers might be particularly sensitive to such moments (Russo et al., 2020, p. 9).

Within their discussion of the enjoyment derived from supporting students to make connections, teachers sometimes made specific reference to students overcoming struggle and persisting in the face of adversity as a precursor to these light bulb moments:

We gave them the first experience; the students did struggle so we decided, as a team, that we would reintroduce it again... So, being able to take them back a step and see them struggle and then see them come out the other end where they can achieve. So, that's been enjoyable making sure that all my students have success and they're not feeling that they can't achieve... Sarah 
She was about to cry, and she said 'I don't think I can do it', and I just said to her 'Could you use some of the animals to help you?' And off she went, and she did three different combinations within that lesson. And just the excitement that you see on the students when they are able to show that they can do different ways... It's just nice to see that evolution happening with the students... Julie

I love seeing those light bulb moments with those ones that struggle and [then] they get it. Fiona

Again, this is consistent with Russo et al.'s (2020) finding that teachers' valuing opportunities for students to struggle productively is related to teacher enjoyment of teaching mathematics.

Finally, teachers often referenced their satisfaction in observing student emotional responses following these conceptual breakthroughs. Specifically, they valued watching students grow in confidence and take pride in their work:

Just seeing them really grow in their confidence once they saw it a couple of times. Ellen

She did it really confidently, and like she got the concept, like she understood what she needed to do, and she did it... I'm spending all this time on it, and then when she finally got it. I found that really enjoyable, because she was so proud of herself. Jen

They were proud of themselves... and they understood it. That's what you're a teacher for really... When they're lifted and they're like - you can see them walking out with their chest out, that's what you want as a teacher. Penelope

There's one particular girl that pops into my mind. She kind of doesn't get things very easily... [In this particular lesson] I called everybody over to her desk... 'Please explain what you've done. It's fantastic,' and she was just absolutely over the moon... [Then] she just had the sequence in her head, 'this is what I did yesterday, how can I build on that?' So that was really rewarding. Jane

These final quotes emphasise the iterative and mutually reinforcing relationship between student enjoyment of learning mathematics and teacher enjoyment of teaching mathematics, consistently reported in the literature (Frenzel et al., 2009; 2018).

\section{Conclusions and implications}

The aim of the study was to explore high-enjoyment teachers' attitudes towards teaching and learning mathematics across their life span. In addition, we also wished to examine what it was specifically about teaching mathematics that these teachers found enjoyable. Based on self-determination theory (Deci \& Ryan, 2012), we proposed that teacher enjoyment could be conceived as an outcome experienced by teachers that have the three fundamental psychological needs of autonomy, 
competence, and relatedness met when teaching mathematics. For instance, we anticipated that teachers who have their need met for feeling competent as a teacher of mathematics will more likely derive enjoyment from instances when their students demonstrate deep understanding of mathematics (e.g. light bulb moments). We also suggested that the positive emotional responses generated by such moments are likely to satisfy their need for relatedness, once again leading to enjoyment. Findings of the study do indeed support the notion of examining teacher enjoyment of teaching mathematics through a self-determination theory lens. Interpreting the interview data through such a lens sheds light on the reasons why and how this group of early years primary teachers report high enjoyment of teaching mathematics.

Regarding their attitudes towards learning and teaching mathematics, teachers' accounts revealed that turning point experiences (Guillaume \& Kirtman, 2010) are common amongst high-enjoyment primary teachers. They are at least as likely to report a negative-to-positive turning point, as to have experienced consistently positive feelings towards mathematics throughout their lifespans (Ellsworth \& Buss, 2000). In terms of a self-determination theory lens, positive experiences stemming from consistent feelings of confidence in their content knowledge (e.g. Penelope, Dane, Jen) or a sudden growth in their relational understanding of mathematics (e.g. Jane, Fiona, Sarah, Larissa, Julie) contributed to meeting teachers' needs for competence. Hence, initial feelings of competence were further fuelled, leading to increased teacher enjoyment of teaching mathematics when their own students expressed deep understanding of mathematical concepts.

Similarly, teachers reported deriving enjoyment from specific lessons when students appeared engaged and particularly when they witnessed students overcoming struggle as a precursor to developing some new and deep mathematical understanding. Self-determination theory suggests that such instances would help fulfil teachers' psychological need for relatedness, and we propose will thereby enhance teacher enjoyment of teaching.

Three limitations of the study should be noted. First, participants were selected on a convenience basis. It is possible that school leadership that seeks out professional learning opportunities for their teachers, as was the case in the current study, tends to have teachers who enjoy teaching mathematics more (or less) than other schools. Second, findings are specific to generalist primary teachers currently teaching in the early years of schooling from one system of education within an Australian context. It would be worthwhile exploring if the experiences reported by this group of teachers are common to upper primary teachers and to teachers from other cultural contexts. Third, while our sample size was small, the depth of interviews provided quality data, allowing our exploratory study of high-enjoyment teachers of mathematics to shed light on important relationships between teachers and their students while involved in mathematics lessons. Nevertheless, there is value in conducting larger-sized studies that might also incorporate other forms of data collection methods, such as classroom observations that would allow the nature of the interactions between high-enjoyment early-years teachers and their students to be studied during mathematics lessons. 
Our findings have important implications for practice and suggest fruitful directions for future research to pursue. Consider the Aha and light bulb moments described by our study teachers, which were so highly valued. Although from their descriptions teachers played an active role in facilitating these moments, in no instances did these important breakthroughs in student learning appear to arise from teachers explicitly teaching a concept. Rather, from their descriptions, it was tasks for which students do the thinking, rather than the teacher, that generated such moments and the associated experience of joy. One hypothesis emerging from this observation is that a shift to using resources and pedagogies that prompt and privilege student thinking (and structured inquiry) can increase teacher enjoyment. Such a hypothesis could be directly tested more systematically by examining changes in levels of teacher enjoyment following a shift to using such resources and associated pedagogies.

Building on from this, it is a critical observation that one need not be a "maths person' to come to love teaching mathematics; on the contrary, positive experiences in one's pre-service teacher education, or in-service teacher professional learning, can transform one's attitude towards teaching mathematics. Specifically, at least some teachers with a superficial, largely instrumental understanding of mathematics who are given opportunities to develop a richer, relational understanding not only deepen their mathematical and pedagogical content knowledge but also increase their enjoyment of teaching the subject. In fact, having prior negative experiences with mathematics might even buoy such teachers, armed with new knowledge and understandings, to become even stronger advocates for reform-oriented mathematics education in order to provide positive, corrective experiences for their own students. Such interactions between personal mathematical narratives (including any 'turning points'), mathematical content and pedagogical knowledge, endorsement of reformoriented pedagogies and attitudes towards teaching mathematics could be more comprehensively explored in future research.

Funding The research that formed the basis of this article was funded by the Australian Research Council, Catholic Education Diocese of Parramatta, and Catholic Education Melbourne (LP 180100611). The views expressed are the opinions of the authors who take full responsibility for the ethical conduct of the research and preparation of the report.

\section{Declarations}

Ethical approval The study was conducted according to the guidelines of the Declaration of Helsinki and approved by the Ethics Committee of Monash University (Project 10791). All participant names used in the manuscript are pseudonyms.

Informed consent Informed consent was obtained from all the participants involved in the study.

Conflict of interest The authors declare that they have no conflicts of interest.

Open Access This article is licensed under a Creative Commons Attribution 4.0 International License, which permits use, sharing, adaptation, distribution and reproduction in any medium or format, as long as you give appropriate credit to the original author(s) and the source, provide a link to the Creative 
Commons licence, and indicate if changes were made. The images or other third party material in this article are included in the article's Creative Commons licence, unless indicated otherwise in a credit line to the material. If material is not included in the article's Creative Commons licence and your intended use is not permitted by statutory regulation or exceeds the permitted use, you will need to obtain permission directly from the copyright holder. To view a copy of this licence, visit http://creativecommons.org/ licenses/by/4.0/.

\section{References}

Beilock, S. L., Gunderson, E. A., Ramirez, G., \& Levine, S. C. (2010). Female teachers' math anxiety affects girls' math achievement. Proceedings of the National Academy of Sciences, 107(5), 18601863. https://doi.org/10.1073/pnas.0910967107.

Brady, P., \& Bowd, A. (2005). Mathematics anxiety, prior experience and confidence to teach mathematics among pre-service education students. Teachers and Teaching, 11(1), 37-46. https:// doi.org/10.1080/1354060042000337084.

Braun, V., \& Clarke, V. (2006). Using thematic analysis in psychology. Qualitative Research in Psychology, 3(2), 77-101. https://doi.org/10.1191/1478088706qp063oa.

Buckley, S., Reid, K., Goos, M., Lipp, O. V., \& Thomson, S. (2016). Understanding and addressing mathematics anxiety using perspectives from education, psychology and neuroscience. Australian Journal of Education, 60(2), 157-170.

Bursal, M., \& Paznokas, L. (2006). Mathematics anxiety and preservice elementary teachers' confidence to teach mathematics and science. School Science and Mathematics, 106(4), 173-180. https://doi. org/10.1111/j.1949-8594.2006.tb18073.x.

Bush, W. S. (1989). Mathematics anxiety in upper elementary school teachers. School Science and Mathematics, 89(6), 499-509. https://doi.org/10.1111/j.1949-8594.1989.tb11952.x.

Deci, E. L., \& Ryan, R. M. (2012). Self-determination theory. In P. A. M. Van Lange, A. W. Kruglanski, \& E.T. Higgins (Eds.), Handbook of Theories of Social Psychology (Vol. 1; pp. 416-433). Thousand Oaks, CA: Sage. https://doi.org/10.4135/9781446249215.n21.

Drake, C. (2006). Turning points using teachers mathematics life stories to understand the implementation of mathematics education reform Journal of Mathematics Teacher Education, 9(6), 579608. https:// doi.org/10.1007/s10857-006-9021-9.

Ellsworth, J. Z., \& Buss, A. (2000). Autobiographical stories from preservice elementary mathematics and science students: Implications for K-16 teaching. School Science and Mathematics, 100(7), 355-364. https://doi.org/10.1111/j.1949-8594.2000.tb18177.x.

Frenzel, A. C. (2014). Teacher emotions. In R. Pekrun \& E. A. Linnenbrink-Garcia (Eds.), International Handbook of Emotions in Education (pp. 494-519). New York, NY: Taylor \& Francis. https://doi. org/10.4324/9780203148211.ch25.

Frenzel, A. C., Becker-Kurz, B., Pekrun, R., \& Goetz, T. (2015). Teaching this class drives me nuts! Examining the person and context specificity of teachers' emotions. PLoS One, 10, e0129630. https:// doi.org/10.1371/journal.pone.0129630.

Frenzel, A. C., Becker-Kurz, B., Pekrun, R., Goetz, T., \& Lüdtke, O. (2018). Emotion transmission in the classroom revisited: a reciprocal effects model of teacher and student enjoyment. Journal of Educational Psychology, 110(5), 609e628. https://doi.org/10.1037/edu0000228.

Frenzel, A. C., Fiedler, D., Marx, A. K. G., Reck, C., \& Pekrun, R. (2020). Who enjoys teaching, and when? Between-and within-person evidence on teachers' appraisal-emotion links. Frontiers in Psychology, 11. https://doi.org/10.3389/fpsyg.2020.01092.

Frenzel, A. C., \& Goetz, T. (2007). Teachers' emotional experiences during teaching. Zeitschrift fur Padagogische Psychologie, 21(3-4), 283-295. https://doi.org/10.1024/1010-0652.21.3.283.

Frenzel, A. C., Goetz, T., Lüdtke, O., Pekrun, R., \& Sutton, R. E. (2009). Emotional transmission in the classroom: exploring the relationship between teacher and student enjoyment. Journal of Educational Psychology, 101(3), 705e716. https://doi.org/10.1037/a0014695.

Frenzel, A. C., Pekrun, R., Goetz, T., Daniels, L. M., Durksen, T. L., Becker-Kurz, B., et al. (2016). Measuring teachers' enjoyment, anger, and anxiety: the Teacher Emotions Scales (TES). Contemporary Educational Psychology, 46, 148e163. https://doi.org/10.1016/j.cedpsych.2016.05.003. 
Gabriel, F., Buckley, S., \& Barthakur, A. (2020). The impact of mathematics anxiety on self-regulated learning and mathematical literacy. Australian Journal of Education, 64(3), 227-242.

Gresham, G. (2008). Mathematics anxiety and mathematics teacher efficacy in elementary pre-service teachers. Teaching Education, 19(3), 171-184. https://doi.org/10.1080/10476210802250133.

Gresham, G. (2018). Preservice to inservice: does mathematics anxiety change with teaching experience? Journal of Teacher Education, 69(1), 90-107. https://doi.org/10.1177/0022487117702580.

Grootenboer, P., Edwards-Groves, C., \& Rönnerman, K. (2015). The practice of 'middle leading' in mathematics education. In M. Marshman, V. Geiger, \& A. Bennison (Eds.), Mathematics education in the margins: Proceedings of the 38th Annual Conference of the Mathematics Education Research Group of Australasia (pp. 277-284). Sunshine Coast: MERGA.

Guillaume, A. M., \& Kirtman, L. (2010). Mathematics stories: preservice teachers' images and experiences as learners of mathematics. Issues in Teacher Education, 19(1), 121-143.

Haciomeroglu, G. (2014). Elementary pre-service teachers' mathematics anxiety and mathematics teaching anxiety. International Journal for Mathematics Teaching \& Learning. http://www.cimt.org. uk/journal/haciomeroglu.pdf.

Hollingsworth, H. L., \& Knight-McKenna, M. (2018). "I am now confident": academic service-learning as a context for addressing math anxiety in preservice teachers. Journal of Early Childhood Teacher Education, 39(4), 312-327. https://doi.org/10.1080/10901027.2018.1514337.

Marbán, J. M., Palacios, A., \& Maroto, A. (2020). Enjoyment of teaching mathematics among pre-service teachers. Mathematics Education Research Journal. https://doi.org/10.1007/s13394-020-00341-y.

Pekrun, R. (2006). The control-value theory of achievement emotions: assumptions, corollaries, and implications for educational research and practice. Educational Psychology Review, 18(4), 315e341. https://doi.org/10.1007/s10648-006-9029-9.

Russo, J., Bobis, J., Sullivan, P., Downton, A., Livy, S., McCormick, M., \& Hughes, S. (2020). Exploring the relationship between teacher enjoyment of mathematics, their attitudes towards student struggle and instructional time amongst early years primary teachers. Teaching and Teacher Education, 88, 102983. https://doi.org/10.1016/j.tate.2019.102983.

Russo, J., A., \& Russo, T. (2019). Teacher interest-led inquiry: unlocking teacher passion to enhance student learning experiences in primary mathematics. International Electronic Journal of Mathematics Education, 14(3), 701e717. https://doi.org/10.29333/iejme/5843.

Ryan, R. M., \& Deci, E. L. (2017). Self-determination theory: basic psychological needs in motivation, development, and wellness. Guilford Publications. https://doi.org/10.1521/978.14625/28806.

Sexton, M. (2019). Object-motives of mathematics leaders' professional learning leadership during participation in a mathematics project. In G. Hine, S. Blackley, \& A. Cooke (Eds.), Mathematics Education Research: Impacting Practice: Proceedings of the 42nd Annual Conference of the Mathematics Education Research Group of Australasia (pp. 660-667). Perth: MERGA.

Skemp, R. R. (1976). Relational understanding and instrumental understanding. Mathematics Teaching, 77(1), 20-26.

Stipek, D. J., Givvin, K. B., Salmon, J. M., \& MacGyvers, V. L. (2001). Teachers' beliefs and practices related to mathematics instruction. Teaching and Teacher Education, 17(2), 213e226. https://doi. org/10.1016/s0742-051x(00)00052-4.

Sutton, R. E., \& Wheatley, K. F. (2003). Teachers' emotions and teaching: a review of the literature and directions for future research. Educational Psychology Review, 15(4), 327-358. https://doi. org/10.1023/a:1026131715856.

Taxer, J. L., Becker-Kurz, B., \& Frenzel, A. C. (2019). Do quality teacher-student relationships protect teachers from emotional exhaustion? The mediating role of enjoyment and anger. Social Psychology of Education, 22(1), 209-226. https://doi.org/10.1007/s11218-018-9468-4.

Towers, J., Hall, J., Rapke, T., Martin, L. C., \& Andrews, H. (2017). Autobiographical accounts of students' experiences learning mathematics: a review. Canadian Journal of Science, Mathematics and Technology Education, 17(3), 152-164. https://doi.org/10.1080/14926156.2016.1241453.

Publisher's Note Springer Nature remains neutral with regard to jurisdictional claims in published maps and institutional affiliations. 